\title{
Diffusion Tensor Imaging without Complex Statistical Analysis Could Be Helpful for Diagnosis
}

\author{
Duzgun Yildirim¹, Deniz Alis²*, Cesur Samanci², Fethi Emre Ustabasioğlu², Onur Tutar², Atilla Ersen³ \\ ${ }^{1}$ Department of Radiology, Acibadem Taksim Hospital, Istanbul, Turkey \\ ${ }^{2}$ Department of Radiology, Cerrahpasa Medical Faculty, Istanbul University, Istanbul, Turkey \\ ${ }^{3}$ Department of Pediatrics, Kasımpasa Military Hospital, Istanbul, Turkey \\ Email: yildirimduzgun@yahoo.com, *drdenizalis@gmail.com, cesursamanci@gmail.com, ustabasioglu@hotmail.com, \\ onurcpasa@gmail.com, atillaersen@hotmail.com
}

How to cite this paper: Yildirim, D., Alis, D., Samanci, C., Ustabasioğlu, F.E., Tutar, O. and Ersen, A. (2016) Diffusion Tensor Imaging without Complex Statistical Analysis Could Be Helpful for Diagnosis. Open Journal of Medical Imaging, 6, 93-101. http://dx.doi.org/10.4236/ojmi.2016.63009

Received: July 6, 2016

Accepted: September 26, 2016

Published: September 29, 2016

Copyright $\odot 2016$ by authors and Scientific Research Publishing Inc. This work is licensed under the Creative Commons Attribution International License (CC BY 4.0).

http://creativecommons.org/licenses/by/4.0/

\section{Abstract}

Objective: Thanks to fast developing technology, visualization of fiber tracts at brain is possible. But with the new developments, data processing and interpretation are becoming more difficult. Actually interpretations in these fields are mostly in-group analysis and are generally not useful on the basis of individual patient evaluations. In these regards, we investigated our cases with diffusion tensor imaging (DTI) and tried to show if the data could be interpreted simply by radiologist's eye or not. Material: Our study consisted of 31 cases that were evaluated in our center with 3 Tesla Magnetic Resonance Imaging (MRI) units. Cranial DTI studies performed for ischemia, posttraumatic axonal injury, congenital malformation, neoplasia, autism, mental retardation and epilepsy. Cranial DTI was performed to demonstrate effected fiber tracts in neoplasia and ischemia cases and was applied to identify any gross anomaly in microstructural anatomy beside normal conventional MRI in other cases. DTI images were evaluated, along with fused conventional T1 weighted 3D high-resolution images and FA maps. DTI were performed at the first administration of the patients. Results: In addition to chronic ischemic focuses in patients with ischemia, DTI-FA images showed us relevant signal changes secondary to Wallerian degeneration in two cases. In traumatic brain injury cases, though being isointense on conventional sequences, FA values showed decreased values at the levels of the axonal discontinuity. Major abnormalities of association and projection fibers in congenital malformation cases were visualized at both 3D-DTI fused images and FA map images. Displacement, infiltration, destruction fibers were clearly visualized in neoplasia cases. However, any objective abnormality wasn't reported at any cases diagnosed with motor mental retardation, epilepsy or neuropsychiatric diseases. Conclusion: Colored DTI images and FA maps are helpful in the way of diagnosis in most cases with organic 
pathologies; it is possible to obtain diagnostic information by vivacious images.

\section{Keywords}

Central Nervous System, DTI, FA, MRI

\section{Introduction}

Thanks to fast developing technology, visualization of fiber tracts at brain is possible.

The capability of diffusion tensor imaging (DTI) to reliably display secondary alterations of the white matter tracts caused by the primary pathology has the potential to be of great utility for treatment planning and follow-up in near future. With the advancements in diffusion-weighted imaging during the past decade, DTI can now show neuronal tracts in the brain and spine and better characterize the structural integrity of neural tissue [1]. This progress led to new clinical applications of this technique for diagnosis and surgical follow-up protocols of central nervous system pathologies [2] [3].

Interpretations in the fields are more quantitative such as in-group analysis, but they are composed of information out of medical field, and are generally not useful on the basis of individual patient evaluations. In these regard, we investigated our cases' DTI images and tried to show if the data could be interpreted simply with radiologist's eye or not.

\section{Material and Methods}

The local ethics committee of Istanbul University Cerrahpasa Medical Faculty approved the study protocol. Written informed consent was obtained from all patients. In this study, 31 cases requiring advanced imaging with magnetic resonance imaging (MRI) and DTI were evaluated in our center with 3 Tesla MRI. Cranial DTI studies were performed for ischemia (5 cases), posttraumatic axonal injury (4 cases), congenital malformation ( 5 cases), neoplasia ( 7 cases), autism ( 2 cases), mental retardation ( 2 cases), epilepsy ( 3 cases). Cervical DTI investigations were performed for mass ( 2 cases) and syrinx formation (1 case). DTI images were evaluated, along with fused conventional T1 weighted 3D high-resolution images and FA maps. Basic demographic characteristics of the patients were summarized in Table 1 .

\section{Results}

All patients in ischemic group with chronic ischemic focuses who were identified by clinical history and conventional images showed us decreased FA values especially thorough the affected areas. Additionally, DTI-FA images showed relevant signal changes secondary to Wallerian degeneration in two cases (Figure 1).

In traumatic brain injury (TBI) cases, at the levels of the axonal discontinuity where FA values decreased, only SWI sequences showed microhemorrhagic substance superposition. No other sequences showed these microhemorrhagic pathologies in this group 
Table 1. Basic demographic characteristics of the patients.

\begin{tabular}{|c|c|c|c|}
\hline $\begin{array}{c}\text { Patients } \\
(\mathrm{n}=\text { number })\end{array}$ & $\begin{array}{l}\text { Mean } \\
\text { age }\end{array}$ & $\begin{array}{l}\text { Gender } \\
\text { (m: male, } \\
\text { f: fmale) }\end{array}$ & Clinical-radiological findings \\
\hline Ischemia (5) & 47 & $1 \mathrm{f}, 4 \mathrm{~m}$ & $\begin{array}{l}\text { Hemspheric white and gray matter gliotic changes } \\
\text { due to previous ischemia }\end{array}$ \\
\hline Trauma (4) & 32 & $1 \mathrm{f}, 3 \mathrm{~m}$ & $\begin{array}{l}\text { Confusion due to previous trauma which } \\
\text { compatible with diffuse axonal injury }\end{array}$ \\
\hline Malformation (5) & 12 & $2 \mathrm{f}, 3 \mathrm{~m}$ & $\begin{array}{l}\text { Corpus callosum dysgenesis }(\mathrm{n}=4) \text {, vascular } \\
\text { malformation }(\mathrm{n}=1)\end{array}$ \\
\hline Neoplasia (7) & 58 & $3 \mathrm{f}, 4 \mathrm{~m}$ & $\begin{array}{l}\text { Gliobilastoma multiforme with newly diagnosed }(\mathrm{n}= \\
\text { 5) and recurrent }(\mathrm{n}=2) .\end{array}$ \\
\hline Autism (2) & 9 & $2 \mathrm{~m}$ & $\begin{array}{l}\text { Neuropsychiatric examination and test results } \\
\text { compatible with autism spectrum disorders }\end{array}$ \\
\hline $\begin{array}{l}\text { Mental } \\
\text { retardation (2) }\end{array}$ & 11 & $2 \mathrm{~m}$ & $\begin{array}{l}\text { Neuropsychiatric examination and test results } \\
\text { compatible with autism spectrum disorders }\end{array}$ \\
\hline Epilepsy (3) & 17 & $2 \mathrm{f}, 1 \mathrm{~m}$ & Partial convulsions and positive EEG findings \\
\hline $\begin{array}{l}\text { Cervical spine mass }(2), \\
\text { syrinx }(1)\end{array}$ & 42 & $2 \mathrm{f}, 1 \mathrm{~m}$ & $\begin{array}{c}\text { Thermal and sensory dissociations of upper } \\
\text { extremities and positive neurologic examination } \\
\text { findings }\end{array}$ \\
\hline
\end{tabular}

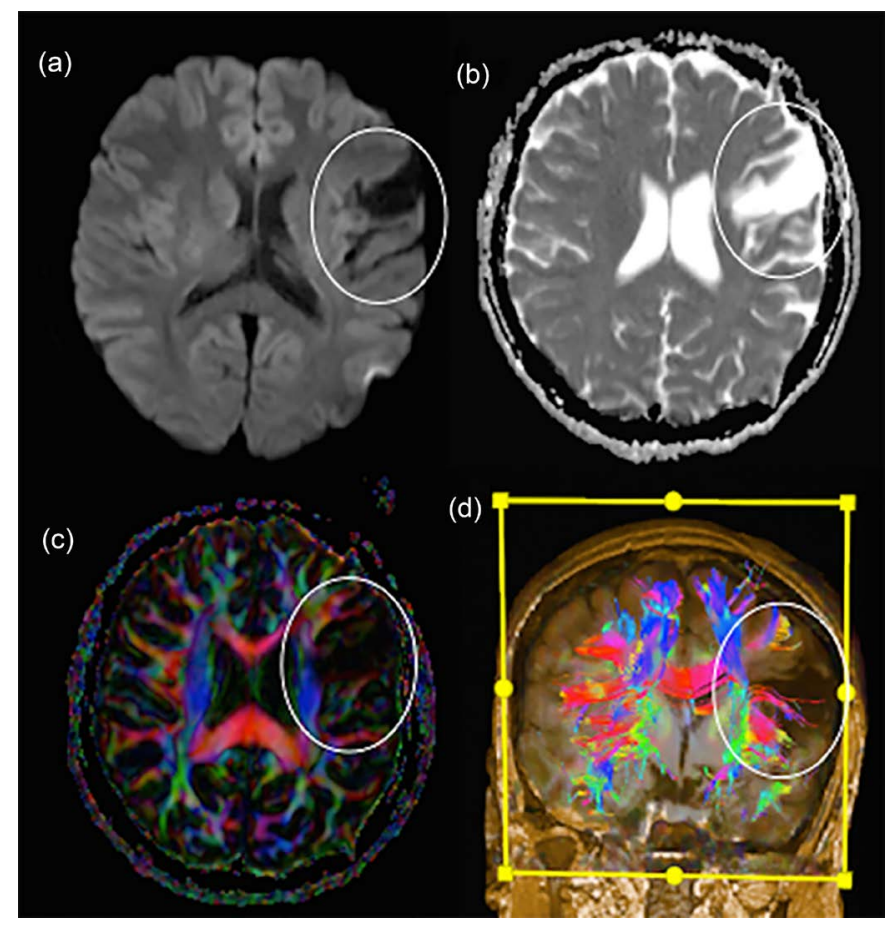

Figure 1. A case with encephalomalasic changes due to old ischemia. (a) b-1000 image, (b) ADC map, (c) colored FA map, (d) three dimensional fused images of tractography maps show the absence of fibers without any displacement or infiltrative changes (encircled area).

of patients. Neurological findings were suggested axonal injury in these cases, however conventional MRI sequences were normal. On the other hand, DTI-FA maps were compatible with SWI and clinical findings (Figure 2). 


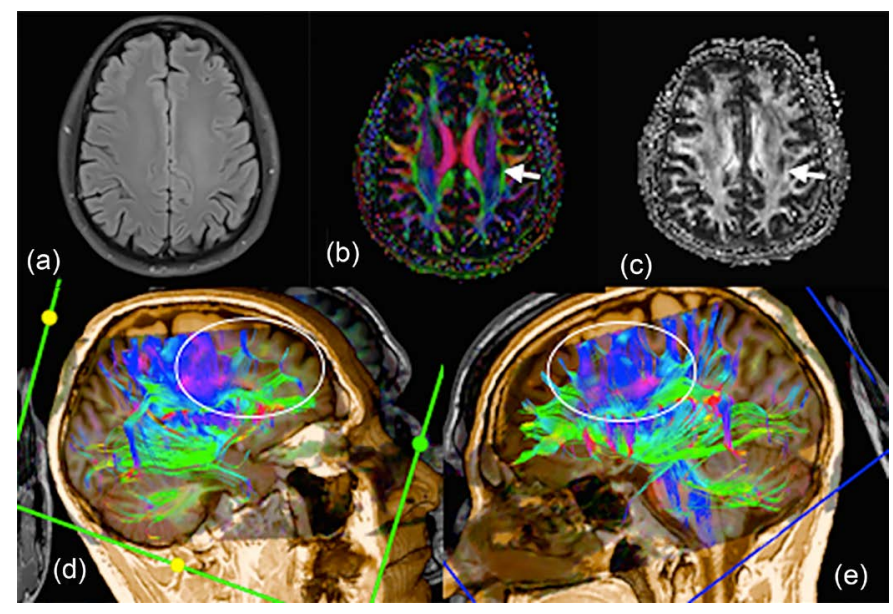

Figure 2. In cases with traumatic brain injury (TBI). (a) At high resolution axial FLAIR image, in coloured (b) and gray scale (c) FA maps; at the levels of axonal discontinuity where FA values decreased as darkened focus (arrows) seen objectively. No other any sequence showed these old posttraumatic abnormalities in this case. Abnormal side generally has reduced frontal association fibers compared to normal side at 3D-T1 fusion color tractography maps.

Major abnormalities of association and projection fibers in congenital malformation cases could be visualized at both 3D-DTI fused images and FA map images. DTI sequences were able to identify abnormal connectivity in anomalies, which mainly effected corpus callosum.

However, any objective anatomical pathology weren't reported at cases with motor mental retardation, epilepsy or neuropsychiatric diseases in DTI evaluations. Only some minor changes were identified (as uncinate fascicilus asymmetry or decreased FA values in corpus callosum etc.) which were consistent with literatures (Figure 3).

Displacement, infiltration, destruction of $U$ fibers, major association and projection fibers could be clearly visualized in intracranial neoplasia cases (Figure 4). It was possible to differentiate malign lesions from benign ones according effected fibers.

Cervical spinal cord DTI was performed in 3 cases, mass or syrinx localization and its association with fiber tracts could clearly be visualized. These cases were diagnosed as syringomyelia rather than hydromyelia. Clinical and neurological findings of these cases were compatible with advanced radiological findings.

As commonly described, follow-up data and clinical data were correlated with these advanced radiological evaluations and compatibility with clinical data was investigated. Special images for each group were processed separately.

\section{Discussion}

Diffusion tensor imaging is a promising method for characterizing microstructural changes and may be helpful in finding the essential cause of abnormality in patients. In this paper, contrary to definite special technical applications (physics, mathematics, mechanism) or complicated statistical analyses, high-resolution DTI images are evaluated simply by visual calculations. 


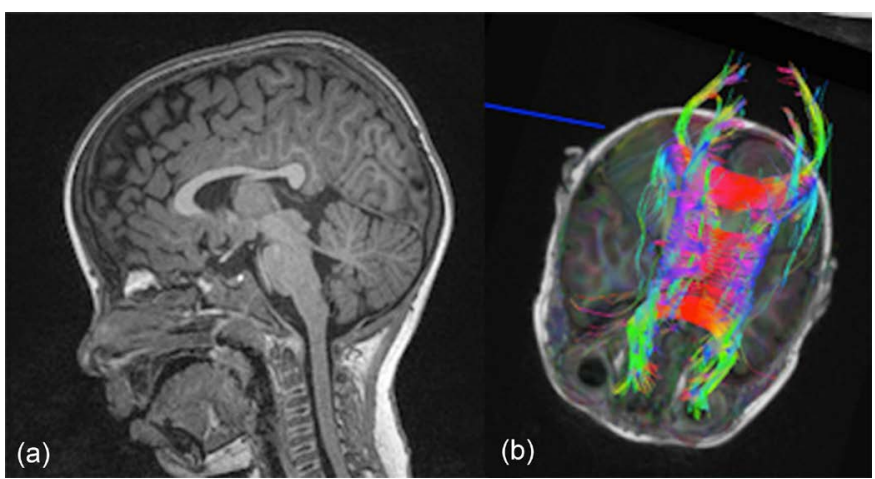

Figure 3. A young man with autism spectrum disorders (a) though to normal callosal anatomy at sagittal T1 weighted image, (b) crossing fibers were very sparked at fused, colored tractography image.

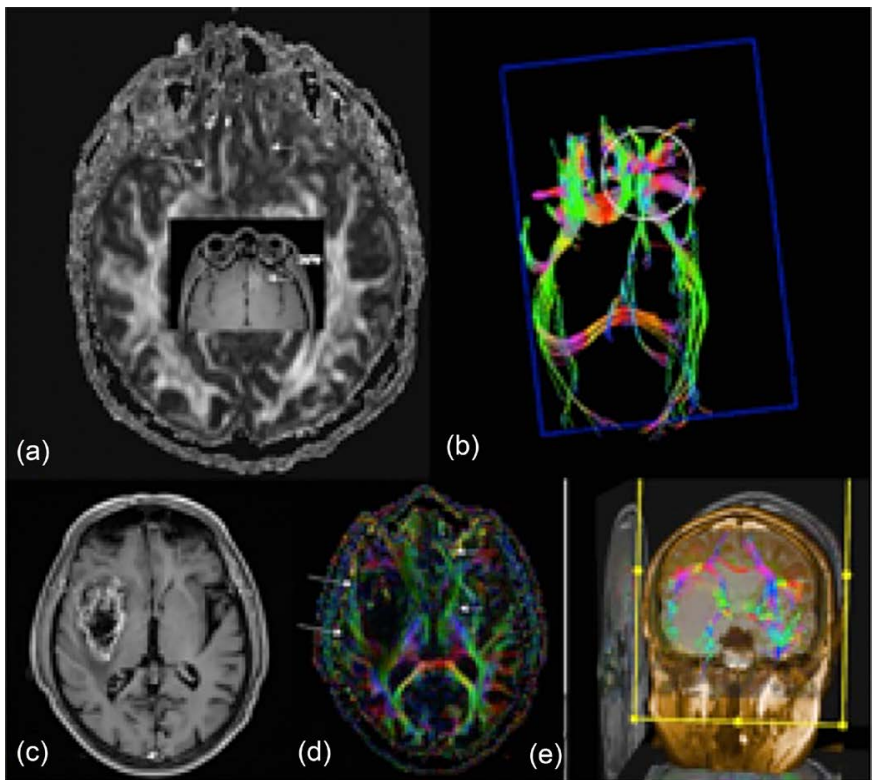

Figure 4. Displacement, infiltration and destruction of $U$ fibers, major association and projection fibers could be clearly visualized in intracranial neoplasia cases. (a) A case with left frontobasal cortical capillary malformation (at smaill picture, enhanced area, arrow) shows only thinned short association fibers in FA maps (at background picture, short arrow) compared with normal right side (at background picture, long arrow). (b) At three dimensional fiber tract map, the organization of the fibers is protected without any obvious deformation (encircled area). However in a case with right basal ganglionic GMB; pathological rim enhancement and central necrosis is seen on T1 weighted axial image (c). In this case, colored FA map (d) and fused three dimensional fiber tractography image (e) show deformation and destruction of insular " $u$ " fibers, internal and external capsules (arrows) compared with left side.

There are many signs and demonstrative abnormalities defined by DTI protocol. New techniques are currently being developed based on DTI as DSI (diffusion spectrum imaging), kurtosis, Q-ball imaging etc., since his area is subject of ongoing researches.

Methods for the acquisition and analysis of DTI are rapidly evolving. While the 
complexity is getting problem, the need for enhanced evolution methods are also accelerating with the new developments in this area; for instance while the number of the vectors are increasing, capacity and speed of the processors should increase to exceptional levels.

In simple terms, complex operation mechanism of DTI consist of appliance of at least 6 different directions of diffusion gradient and determination of varying degrees of movement limitations water molecules undergo along fiber tracts in their microenvironments [2].

The last range of parameters that can be extracted from the DTI concept relates to the mapping of tissue structure orientation in space. Here gathered data are quantified and mapped as mean diffusivity and fractional anisotrophy and organized as gray scale and colored maps. Roi measurements and calculations can be done using these maps [3]. It is important to notice that diffusion imaging is a truly quantitative method, because diffusion coefficient calculated is a parameter that directly reflects the physical properties of the tissues. Chan et al. investigated the affects of hypoxic ischemic encephalopathy on visual pathways and found retinocollicular and retino geniculate pathways were more vulnerable to anterograde degeneration from eye injury than retrograde, trans synaptic degeneration from visual cortex injury [4].

Nael et al. showed in hyper acute ischemic stroke while all sequence values could be in normal limits. FA values could increase suddenly and as process becoming chronic FA values diminished [5].

TBI cases in our study showed decreased FA values. Robert et al. with a mataanalysis showed in the same patient group that FA increased and ADC decreased in most white matter tracts in the short-term, and FA decreased and ADC increased in medium to long-term [6].

In a study, relationship between mild TBI and mental state was showed clearly with in vivo DTI examination [7].

Congenital anomalies, variations and a large variety of diseases changing from simple callosal dysgenesis to otism could be diagnosed by showing fiber course anomalies, agenesis and aberrations in great detail when compared with conventional sequences [8]-[11].

Choudhri et al. showed in their article the effectiveness and success of the commisural dissection could be tested by DTI at postoperative stage and also DTI could be used to show displacement, infiltration, destruction of $U$ fibers, major association and projection fibers in intracranial benign or malignant neoplasms. Even post-op course and possible complications of these neoplasms may be estimated through their association with critical association and projection fibers [12].

Several articles reported that pre-operative assessment with the DTI provided helpful information for neurosurgery. Continuously growing numbers of literature data indicate DTI is not only used for demonstration of fiber destruction by tumor invasion but also as a part of multiparametric assessment complex for differential diagnosis and tumor grading [12]-[15]. 
Literatures and our cases showed examination of intramedullary lesions with DTI provided detailed information about the exact localizations, adjacent fiber tract relations of these lesions [12]-[16].

Furthermore, early period damage of spinal cord by non-neoplastic pathologies like disc herniation and possible systemic disorders could be obtained by DTI [17] [18]. Evaluations in this study were made relatively, but data in groups which represent main pathologies were assessed by a single researcher, FA-ROI measurements were not done in most of the cases. Findings were not tested with detailed, inter-group statistical tests, so quantification with some evaluations was not achieved and this may hamper the objectivity. Beside this main restriction, data were presented in consideration with visual evaluations needed for every radiologist without deviation from main aim of the article and usage of the technique and parametric details [19].

On the other hand, this case based article which lacks detailed statistical analysis did not present any specific data about cognitive disorders and neuropsychiatric diseases. However, prominent and promising findings about this group of disorders appear continuously throughout the literatures and numbers of related articles are progressively increasing [20] [21]. Some articles showed degree of hazards in central nervous system disorders by inflammatory intestinal diseases, SLE and Hepatitis B virus infections could be evaluated by some metric and statistical measurements of DTI [22]-[26]. We believed that if methods like tract based analysis might be simplified in the future, these methods could be very valuable for the detection of microstructural anomalies, which is unable to be detected visually.

\section{Conclusion}

In conclusion, although it doesn't provide concrete and case-specific valuable information to radiologists, especially in cases with microstructural anomalies like neuropsychiatric disorders, epilepsy and motor-mental retardation; in most cases with organic pathologies, it is possible to obtain diagnostic information by DTI-FA maps and 3D-tractography's vivacious images. Indeed, currently used statistical analysis programs could show microstructural anomalies as well as growing steadily and this area is the subject of ongoing research.

\section{References}

[1] Lerner, A., Mogensen, M.A., Kim, P.E., Shiroishi, M.S., Hwang, D.H. and Law, M. (2014) Clinical Applications of Diffusion Tensor Imaging. World Neurosurgery, 82, 96-109. http://dx.doi.org/10.1016/j.wneu.2013.07.083

[2] de Carvalho Rangel, C., Hygino Cruz Jr., L.C., Takayassu, T.C., Gasparetto, E.L. and Domingues, R.C. (2011) Diffusion MR Imaging in Central Nervous System. Magnetic Resonance Imaging Clinics of North America, 19, 23-53. http://dx.doi.org/10.1016/j.mric.2010.10.006

[3] Vargas, M.., Delavelle, J., Jlassi, H., Rilliet, B., Viallon, M., Becker, C.D. and Lövblad, K.O. (2008) Clinical Applications of Diffusion Tensor Tractography of the Spinal Cord. Neuroradiology, 50, 25-29. http://dx.doi.org/10.1007/s00234-007-0309-y 
[4] Chan, K.C., Kancherla, S., Fan, S.J. and Wu, E.X. (2014) Long-Term Effects of Neonatal Hypoxia-Ischemia on Structural and Physiological Integrity of the Eye and Visual Pathway by Multimodal MRI. Investigative Ophthalmology \& Visual Science, 56, 1-9. http://dx.doi.org/10.1167/iovs.14-14287

[5] Nael, K., Trouard, T.P., Lafleur, S.R., Krupinski, E.A., Salamon, N. and Kidwell, C.S. (2015) White Matter Ischemic Changes in Hyperacute Ischemic Stroke: Voxel-Based Analysis Using Diffusion Tensor Imaging and MR Perfusion. Stroke, 46, 413-418. http://dx.doi.org/10.1161/STROKEAHA.114.007000

[6] Roberts, R.M., Mathias, J.L. and Rose, S.E. (2014) Diffusion Tensor Imaging (DTI) Findings Following Pediatric Non-Penetrating TBI: A Meta-Analysis. Developmental Neuropsycholo$g y$, 39, 600-637. http://dx.doi.org/10.1080/87565641.2014.973958

[7] Xiong, K., Zhu, Y., Zhang, Y., Yin, Z., Zhang, J., Qiu, M. and Zhang, W. (2014) White Matter Integrity and Cognition in Mild Traumatic Brain Injury Following Motor Vehicle Accident. Brain Research, 23, 86-92. http://dx.doi.org/10.1016/j.brainres.2014.10.030

[8] Eshetu, T., Meoded, A., Jallo, G.I., Carson, B.S., Huisman, T.A. and Poretti, A. (2014) Diffusion Tensor Imaging in Pediatric Chiari Type I Malformation. Developmental Medicine \& Child Neurology, 56, 742-748.

[9] Beckett, J.S., Brooks, E.D., Lacadie, C., et al. (2014) Altered Brain Connectivity in Sagittal Craniosynostosis. Journal of Neurosurgery. Pediatrics, 13, 690-698.

http://dx.doi.org/10.3171/2014.3.PEDS13516

[10] Oishi, K., Faria, A.V., Yoshida, S., Chang, L. and Mori, S. (2013) Quantitative Evaluation of Brain Development Using Anatomical MRI and Diffusion Tensor Imaging. International Journal of Developmental Neuroscience, 3, 512-524. http://dx.doi.org/10.1016/j.ijdevneu.2013.06.004

[11] Poretti, A., Meoded, A., Rossi, A., Raybaud, C. and Huisman, T.A. (2013) Diffusion Tensor Imaging and Fiber Tractography in Brain Malformations. Pediatric Radiology, 43, 28-54. http://dx.doi.org/10.1007/s00247-012-2428-9

[12] Choudhri, A.F., Whitehead, M.T., McGregor, A.L., Einhaus, S.L., Boop, F.A. and Wheless, J.W. (2013) Diffusion Tensor Imaging to Evaluate Commissural Disconnection after Corpus Callosotomy. Neuroradiology, 55, 1397-1403. http://dx.doi.org/10.1007/s00234-013-1286-y

[13] Ulmer, J.L., Klein, A.P., Mueller, W.M., De Yoe, E.A. and Mark, L.P. (2014) Preoperative Diffusion Tensor Imaging: Improving Neurosurgical Outcomes in Brain Tumor Patients. Neuroimaging Clinics of North America, 24, 599-617. http://dx.doi.org/10.1016/j.nic.2014.08.002

[14] Jiang, R., Du, F.Z., He, C., Gu, M., Ke, Z.W. and Li, J.H. (2014) The Value of Diffusion Tensor Imaging in Differentiating High-Grade Gliomas from Brain Metastases: A Systematic Review and Meta-Analysis. PLoS ONE, 9, e112550. http://dx.doi.org/10.1371/journal.pone.0112550

[15] Inano, R., Oishi, N., Kunieda, T., Arakawa, Y., et al. (2014) Voxel-Based Clustered Imaging by Multiparameter Diffusion Tensor Images for Glioma Grading. NeuroImage: Clinical, 5, 396-407. http://dx.doi.org/10.1016/j.nicl.2014.08.001

[16] Potgieser, A.R., Wagemakers, M., van Hulzen, A.L., de Jong, B.M., Hoving, E.W. and Groen, R.J. (2014) The Role of Diffusion Tensor Imaging in Brain Tumor Surgery: A Review of the Literature. Clinical Neurology and Neurosurgery, 124, 51-58. http://dx.doi.org/10.1016/j.clineuro.2014.06.009

[17] Whitehead, M.T., Klimo Jr., P., Montgomery, B.K. and Boop, F.A. (2014) Diffusion Tensor 
Imaging to Guide Surgical Planning in Intramedullary Spinal Cord Tumors in Children. Neuroradiology, 56, 169-174. http://dx.doi.org/10.1007/s00234-013-1316-9

[18] Liu, X., Germin, B.I. and Ekholm, S. (2011) A Case of Cervical Spinal Cord Glioblastoma Diagnosed with MR Diffusion Tensor and Perfusion Imaging. Journal of Neuroimaging, 21, 292-296. http://dx.doi.org/10.1111/j.1552-6569.2009.00459.x

[19] El Mendili, M.M., Cohen-Adad, J., Pelegrini-Issac, M., et al. (2014) Multi-Parametric Spinal Cord MRI as Potential Progression Marker in Amyotrophic Lateral Sclerosis. PLoS ONE, 9, e95516. http://dx.doi.org/10.1371/journal.pone.0095516

[20] Banaszek, A., Bladowska, J., Szewczyk, P., Podgórski, P. and Sąsiadek, M. (2014) Usefulness of Diffusion Tensor MR Imaging in the Assessment of Intramedullary Changes of the Cervical Spinal Cord in Different Stages of Degenerative Spine Disease. European Spine Journal, 23, 1523-1530. http://dx.doi.org/10.1007/s00586-014-3323-x

[21] Cheng, Y., Xu, J., Yu, H., Nie, B., et al. (2014) Delineation of Early and Later Adult Onset Depression by Diffusion Tensor Imaging. PLoS ONE, 9, e112307. http://dx.doi.org/10.1371/journal.pone.0112307

[22] Knöchel, C., Stäblein, M., Storchak, H., et al. (2014) Multimodal Assessments of the Hippocampal Formation in Schizophrenia and Bipolar Disorder: Evidences from Neurobehavioral Measures and Functional and Structural MR. NeuroImage: Clinical, 26, 134-144. http://dx.doi.org/10.1016/j.nicl.2014.08.015

[23] Teipel, S.J., Walter, M., Likitjaroen, Y., Schönknecht, P. and Gruber, O. (2014) Diffusion Tensor Imaging in Alzheimer's Disease and Affective Disorders. European Archives of Psychiatry and Clinical Neuroscience, 264, 467-483.

http://dx.doi.org/10.1007/s00406-014-0496-6

[24] Nakaaki, S., Sato, J., Torii, K., et al. (2013) Decreased White Matter Integrity before the Onset of Delusions in Patients with Alzheimer's Disease: Diffusion Tensor Imaging. Neuropsychiatric Disease and Treatment, 9, 25-29.

[25] Hughes, M., Sundgren, P.C., Fan, X., Foerster, B., et al. (2007) Diffusion Tensor Imaging in Patients with Acute Onset of Neuropsychiatric Systemic Lupus Erythematosus: A Prospective Study of Apparent Diffusion Coefficient, Fractional Anisotropy Values, and Eigenvalues in Different Regions of the Brain. Acta Radiologica, 48, 213-222. http://dx.doi.org/10.1080/02841850601105825

[26] Schmidt-Wilcke, T., Cagnoli, P., Wang, P., et al. (2014) Diminished White Matter Integrity in Patients with Systemic Lupus Erythematosus. NeuroImage: Clinical, 5, 291-297. http://dx.doi.org/10.1016/j.nicl.2014.07.001 
Submit or recommend next manuscript to SCIRP and we will provide best service for you:

Accepting pre-submission inquiries through Email, Facebook, LinkedIn, Twitter, etc. A wide selection of journals (inclusive of 9 subjects, more than 200 journals)

Providing 24-hour high-quality service

User-friendly online submission system

Fair and swift peer-review system

Efficient typesetting and proofreading procedure

Display of the result of downloads and visits, as well as the number of cited articles

Maximum dissemination of your research work

Submit your manuscript at: http://papersubmission.scirp.org/

Or contactojmi@scirp.org 